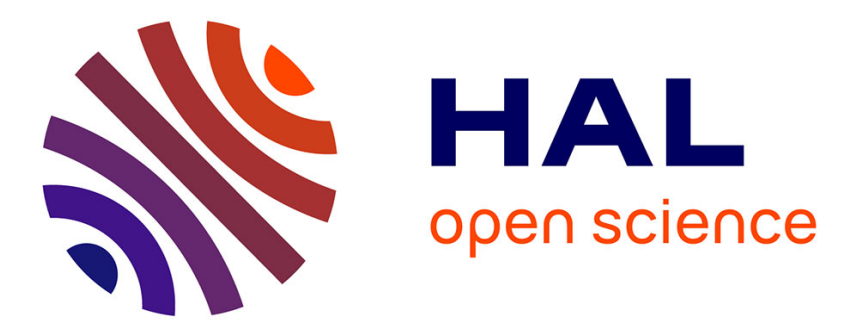

\title{
Binder granulation and compaction of coloured powders
} B N'Dri-Stempfer, Driss Oulahna, Olivier Eterradossi, A Benhassaine, John A. Dodds

\section{To cite this version:}

B N'Dri-Stempfer, Driss Oulahna, Olivier Eterradossi, A Benhassaine, John A. Dodds. Binder granulation and compaction of coloured powders. Powder Technology, 2003, 130 (1-3, SI), p. 247-252. 10.1016/S0032-5910(02)00200-0 . hal-01626712

\section{HAL Id: hal-01626712 https://hal.science/hal-01626712}

Submitted on 22 Feb 2018

HAL is a multi-disciplinary open access archive for the deposit and dissemination of scientific research documents, whether they are published or not. The documents may come from teaching and research institutions in France or abroad, or from public or private research centers.
L'archive ouverte pluridisciplinaire HAL, est destinée au dépôt et à la diffusion de documents scientifiques de niveau recherche, publiés ou non, émanant des établissements d'enseignement et de recherche français ou étrangers, des laboratoires publics ou privés. 


\title{
Binder granulation and compaction of coloured powders
}

\author{
B. N’Dri-Stempfer ${ }^{a}$, D. Oulahna ${ }^{\mathrm{a}, *}$, O. Eterradossi ${ }^{\mathrm{b}}$, A. Benhassaine ${ }^{\mathrm{b}}$, J.A. Dodds $^{\mathrm{a}}$ \\ ${ }^{a}$ Ecole des Mines d'Albi-Carmaux, Laboratoire de Génie des Procédés des Solides Divisés, UMR CNRS 2392, Campus Jarlard, Albi F81013, France \\ ${ }^{\mathrm{b}}$ Groupe "Propriétés Psychosensorielles des matériaux"-Ecole des Mines d'Alès, Hélioparc-2, avenue Angot 64053, Pau, France
}

\begin{abstract}
This paper gives results of a study of compacts made from both a free powder mixture and granules made from this same mixture, and produced by two binder granulation techniques: high shear granulation and fluidised bed granulation. The characteristics of the compacts are analysed in terms of colour and aspect derived from their reflectance spectra and related to the flow properties and bulk density of the components forming the compacts.
\end{abstract}

Keywords: Powder; Densification; Colour; Reflectance spectrum; Wet granulation

\section{Introduction}

The overall volume occupied by a powder, or a mixture of powders, is a variable, which depends on many factors: the possibilities for particle rearrangement, the flow properties and the force exerted on the system. All of these are important factors in processes used to produce powder compacts as they involve both powder flow to fill dies, particle rearrangement followed by compaction under mechanical pressure. Furthermore, it is well known that the final properties of compacts are to a large extent determined by the initial state of the powder before loading, often called the history of the packing. This paper is concerned with analysing the compaction of powders in terms of the structure of the compacts formed. The analysis is based on "colour" here used as an indicator of this structure [1]. In industrial compaction process, the free powder is often pretreated by binder agglomeration so as to fix the powder blend, and enlarge the particle size to improve the flow properties [2]. Such pretreatment by granulation introduces process factors that are not simple, for example, it is well known that the product of a granulation operation comprises a range of granule sizes, but which affect the structure of the compact and also its colour. One of the aims here is to confirm the hypothesis that the resulting overall "colour" of

* Corresponding author (oulahna@mines-albi.fr) a compact formed from a distribution of granule sizes is the sum of the colours of the individual granules.

\section{Materials and methods}

\subsection{Materials}

The material used in this study is a mixture of $99 \%(\mathrm{w} / \mathrm{w})$ of a white powder-75\% (w/w) of microcrystalline cellulose (Avicel ${ }^{\circledR}$ PH105) and 25\% (w/w) talc (Luzenac ${ }^{\circledR}$ Talc) — with $1 \%(\mathrm{w} / \mathrm{w})$ of a blue organic pigment phthalocyanin (Langdocyal ${ }^{\circledR}$ Bleu). The powder blend (Table 1 ) is obtained by successive dilution in a drum mixer, Erweka AR $402^{\circledR}$, at the speed of $15 \mathrm{rpm}$. This blend is named $\mathrm{C}_{75} \mathrm{~T}_{25} \mathrm{P}_{1}$.

\subsection{Granulation process}

Granulation is performed in two types of apparatus using the same binder of a $7.5 \%$ by weight solution in water of hydroxypropyl-methylcellulose (HPMC Pharmacoat $\left.603^{\circledR}\right)$.

- High shear granulation in a Diosna $\mathrm{P} 1 / 6^{\circledR}$ high shear mixer. Two hundred grams of powder is put in the mixer bowl and the binder is dripped in from a burette, to give $0.78 \mathrm{ml} / \mathrm{g}$ of powder. The rotation speed was about 200 rpm for the agitator and the chopper blade. 
Table 1

Properties of the materials

\begin{tabular}{|c|c|c|c|c|c|}
\hline Materials & $\begin{array}{l}\text { True density } \\
\left(\mathrm{g} / \mathrm{cm}^{3}\right)\end{array}$ & $\begin{array}{l}\text { BET specific } \\
\text { surface }\left(\mathrm{m}^{2} / \mathrm{g}\right)\end{array}$ & $\begin{array}{l}\text { Weight median } \\
\text { diameter } d_{50}(\mu \mathrm{m})\end{array}$ & $\begin{array}{l}\text { Span } \\
\frac{d_{90}-d_{10}}{d_{50}}\end{array}$ & $\begin{array}{l}\text { Bulk density } \\
\left(\mathrm{g} / \mathrm{cm}^{3}\right)\end{array}$ \\
\hline $\begin{array}{l}\text { Microcrystalline } \\
\text { cellulose }\end{array}$ & 1.55 & 2.0 & 16 & 2.0 & 0.32 \\
\hline Talc & 2.81 & 1.8 & 10 & 2.2 & 0.49 \\
\hline Blue phthalocyanin & 1.71 & 59.4 & 3 & 2.3 & 0.33 \\
\hline $\mathrm{C}_{75} \mathrm{~T}_{25} \mathrm{P}_{1}$ & 1.74 & 3.6 & 18 & 1.9 & 0.35 \\
\hline
\end{tabular}

- Fluidised bed granulation in a GEA Strea $1^{\circledR}$ fluidised bed granulator. Two hundred grams of powder is put in the fluidised bed with air temperature of $50{ }^{\circ} \mathrm{C}$. Binder is sprayed in at $0.35 \mathrm{~cm}^{3} / \mathrm{s}$ and at a pressure of $1 \mathrm{bar}$, to give $1.53 \mathrm{ml} / \mathrm{g}$ of powder.

\subsection{Densification under load}

Compacts are made from either the free powder mixture or the two types of granule using an Instron $5567^{\circledR}$ instrumented laboratory press at a load of $25 \mathrm{kN}$ with a compression of $10 \mathrm{~mm} / \mathrm{min}$, and the ejection speed is about $5 \mathrm{~mm} / \mathrm{min}$. The compacts are of $3 \mathrm{~cm}$ diameter $\left(7.1 \mathrm{~cm}^{2}\right)$ with amount of material required to fill the half-volume $\left(18.7 \mathrm{~cm}^{3}\right)$ of the die was calculated from the bulk density given in Table 2. The load displacement compression cycle determined in each test is then fitted to two different models as described in Section 3.2.1.

\subsection{Densification by tapping}

The first stage of the compaction cycle involves rearranging the particles and eliminating interstitial air from the powder. This is analogous to following volume changes in a powder caused by tapping. Such experiments were performed with an Erweka SVM $22^{\circledR}$ tap density apparatus with two 250-ml glass-measuring cylinders. The results are expressed in terms of two indexes:

- The Hausner ratio (HR; ratio of the tapped to the aerated bulk density) [3] gives an indication of the cohesion of a powder. When HR is above 1.4, the powder is cohesive, and when it is below 1.25, the powder is granular. A powder with a HR between 1.2 and 1.4 is of intermediate nature.

- The Carr Index (CI) [(tapped density - bulk density)100/ tapped density] [4] is indicative of the powder compressibility and flowability. A powder with a CI below 15\% has a low compressibility and good flow properties. A CI greater than $25 \%$ means that the powder is very compressive and gives very poor flow. Between 15\% and $25 \%$, the powder has intermediate properties.

Many authors have proposed models to predict the evolution of tapped density with the number of taps [57]. Here we use the modified Heckel equation proposed by
$\mathrm{Yu}$ and Hall [5]. In this equation, $\rho_{\infty}$ is the maximum packing density obtained under the given experimental conditions, $\rho_{n}$ is the packing density after $n$ taps, $\rho_{0}$ is the bulk density of powder, $k$ and $s$ are constants:

$\rho_{\infty}-\rho_{n}=\left(\rho_{\infty}-\rho_{0}\right) e^{-k n^{s}}$

\subsection{Colour characterisation}

Each compact is characterised by colour as analysed by its reflectance spectrum [1] (reflected radiation as a function of wavelength) which gives information about the colour (or tint) and the luminosity of a material $[8,9]$. The reflectance $(R(\lambda))$ of a material, defined as the ratio of reflected light flux to incident light flux at each wavelength is measured using a Spectrascan PR650 ${ }^{\circledR}$ spectrophotometer.

When subjected to an incident radiation with a given range of wavelengths, a solid will emit a specific light flux at each wavelength. This spectrum (of $R(\lambda)$ ) indicates those wavelengths where light is absorbed and gives information about the colour (tint) of the material. The area under this curve is the quantity of light reflected, giving the aspect of the material (matt or brilliant). Consequently, a white material will emit at all wavelengths and the signal will be near 1 at each wavelength. A black material will absorb at all wavelengths and its signal will be zero at all wavelengths.

\section{Physical properties of granules}

\subsection{Characteristics of the granules}

The main function of granulation is to enlarge the size of particles. It can be seen in Table 2 that, with respect to the fluidised bed, the high shear mixer gives bigger granules with a wider size distribution which are denser granules and have a higher bulk density. The fluidised bed does result in size enlargement but gives granules having a bulk density close to that of the free powder.

The mechanical properties of the granules can be evaluated by the HR and CI indices. It is found that the Hausner ratio (HR) is improved by granulation and the compressibility (CI) is reduced by granulation. The values in Table 2 indicate that the powder mixture used is very cohesive and has poor flow properties. Furthermore, the mixture is very 
Table 2

Characteristics of powder and granules obtained from the fluidised bed and the high shear mixer

\begin{tabular}{lcllllr}
\hline Materials & $\begin{array}{l}\text { Median diameter } \\
d_{50}(\mu \mathrm{m})\end{array}$ & $\begin{array}{l}\text { Span } \\
d_{90}-d_{10}\end{array}$ & $\begin{array}{l}\text { True density } \\
\left(\mathrm{g} / \mathrm{cm}^{3}\right)\end{array}$ & $\begin{array}{l}\text { Bulk density } \\
\left(\mathrm{g} / \mathrm{cm}^{3}\right)\end{array}$ & $\begin{array}{l}\text { Tapped density } \\
\left(\mathrm{g} / \mathrm{cm}^{3}\right)\end{array}$ & $\begin{array}{l}\text { HR } \\
(\%)\end{array}$ \\
\hline $\begin{array}{l}\text { Free powder } \\
\begin{array}{l}\text { Granules from } \\
\quad \text { fluidised bed }\end{array}\end{array}$ & 18 & 1.9 & 1.74 & 0.35 & 0.47 & 1.4 \\
$\begin{array}{c}\text { Granules from high } \\
\text { shear mixer }\end{array}$ & 200 & 1.6 & 3.83 & 0.28 & 0.33 & 1.2 \\
\hline
\end{tabular}

compressible even though it takes time to achieve a steady state (the plateau is reached after 500 taps-Fig. 1) and the variation of density is quite high (about $0.12 \mathrm{~g} / \mathrm{cm}^{3}$ ).

The granules produced by the fluidised bed have intermediate-type properties, that is, with some inter-particular friction and a reasonable flow. In fact, the fluidised bed restructures particles by forming pseudo-spherical-shaped granules which flow better even though the particle sizes remain small which limits the effects.

The high shear mixer makes bigger and denser granules, forming a granular powder with practically no friction between granules and having excellent flow properties. It can be seen that maximum packing density is rapidly reached (less than 300 taps-Fig. 1) and the variation of density is low (about $0.07 \mathrm{~g} / \mathrm{cm}^{3}$ ).

In conclusion, granulation considerably modifies the size and the packing properties of a powder, which will have an effect on the compaction process. In addition, the mixture homogeneity in the granules and variations in the composition of the different components may also have an effect but has not yet been studied.

\subsection{Effect of granulation on densification properties}

\subsubsection{Densification under load}

Heckel $[10,11]$ has developed a model of the compression cycle expressed in Eq. (2). The parameters can be related to the mechanisms involved and the aptitude of the powders, or the granules, to be ductile or brittle. However, this interpretation of Heckel parameters is very sensitive to

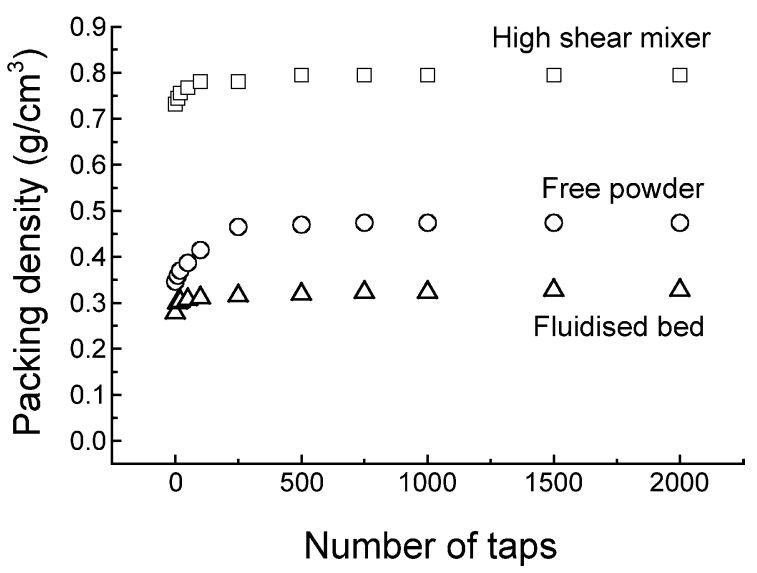

Fig. 1. Packing properties of the free powder and the granules. the errors introduced when measuring the true density of a product [12].

$\ln \left(\frac{1}{1-\rho}\right)=K P+A$

Here, $\rho$ is the relative density of the compact, $P$ the compression pressure, $K$ and $A$ are constants determined by the slope and the intercept of the extrapolated region. It is important to note that $K$ is determined by the linear region of the Heckel model and is the reciprocal of the mean yield pressure $P_{\mathrm{y}}$, which is a measure of the ability of a powder to undergo plastic deformation.

A limitation of the Heckel equation is that it does not give a good fit over the whole density versus pressure curve, especially at low pressure. Kuentz and Leuenberger [13] attribute this limitation to the fact, that in the Heckel equation, the pressure susceptibility is considered to be a constant. By introducing physical notions of phase transitions and critical phenomena, and the fact that pressure susceptibility could be a function of the porosity and the compression pressure, they proposed a modified Heckel equation [13].

$P=\frac{1}{C}\left[\rho_{\mathrm{c}}-\rho-\left(1-\rho_{\mathrm{c}}\right) \ln \left(\frac{1-\rho}{1-\rho_{\mathrm{c}}}\right)\right]$

Here, $P$ is the compression pressure, $C$ a constant, $\rho$ the relative density and $\rho_{\mathrm{c}}$ the critical relative density corresponding to the state where rigidity starts to change.

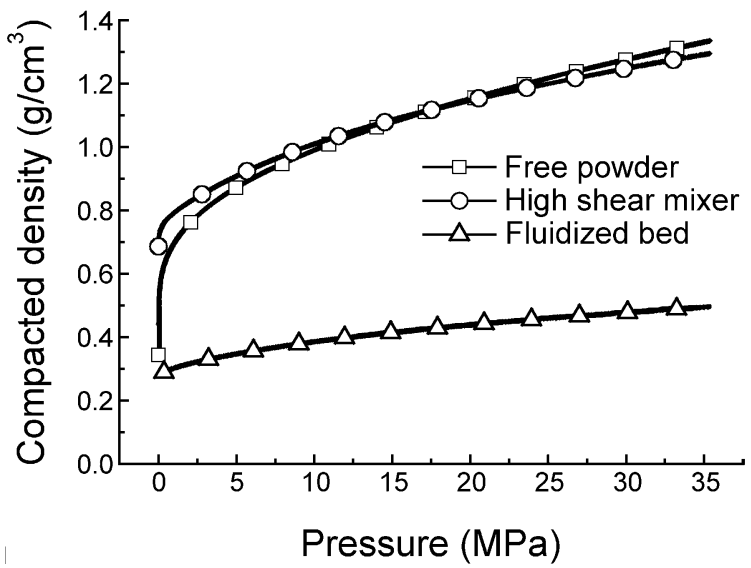

Fig. 2. Effect of granulation on densification under load. 


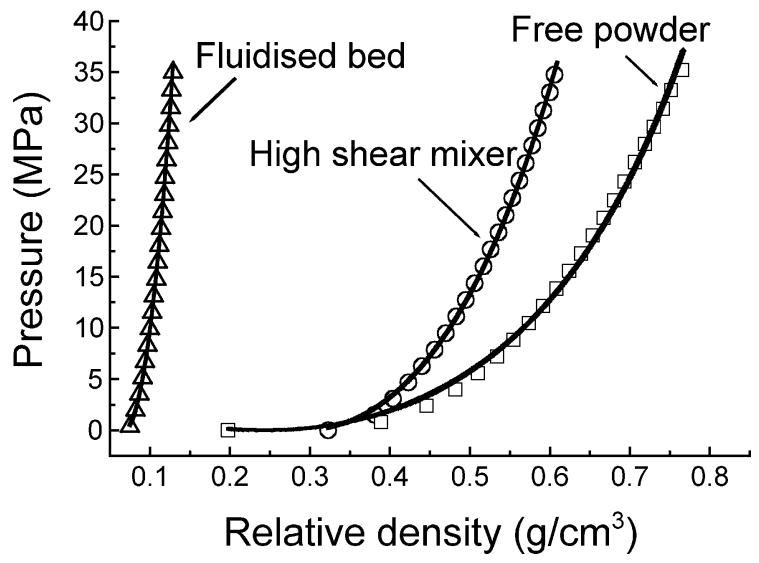

Fig. 3. Compression pressure versus relative density. The solid lines represent the model according to Kuentz and Leuenberger [13] calculated with Eq. (3).

The free powder used here is very compressible and shows large volume changes under load. There is an extensive rearrangement phase, the compaction phase is long (Fig. 2), and the final compact is denser than those formed from granules. The granules from the high shear mixer are found to be slightly more compressible than their behaviour under tapping would indicate. This can be attributed to the fragility of granules, which break under load and can thus better fill the volume. On the other hand, the granules from fluidised bed are found to be less compressible and give the least dense compact.

It is interesting to compare the behaviour of these two types of granules and the free powder under load and to compare the results with the Heckel equation (2) and with the modified Heckel equation (3) due to Kuentz and Leuenberger [13]. It is found that the modified model gives a much better fit to the experimental results for both the free powder and for the granules (Figs. 3 and 4). The

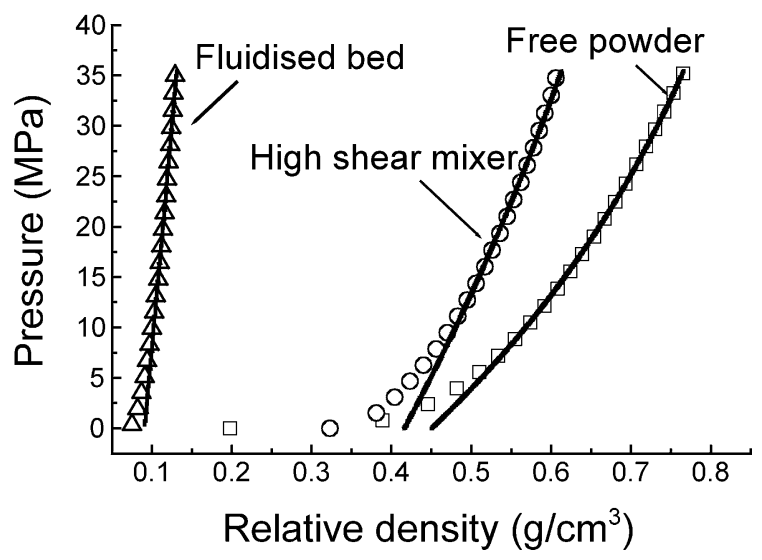

Fig. 4. Compression pressure versus relative density. The solid lines represent the Heckel model calculated with Eq. (2).
Table 3

Comparison between parameters from the Heckel equation (2) and the Heckel equation as modified by Leuenberger (3)

\begin{tabular}{|c|c|c|c|c|c|c|c|}
\hline \multirow[t]{3}{*}{ Materials } & \multicolumn{3}{|c|}{ Heckel equation } & \multirow{2}{*}{\multicolumn{3}{|c|}{$\begin{array}{l}\text { Modified Heckel } \\
\text { equation }\end{array}$}} & \multirow{3}{*}{$\begin{array}{l}\text { Relative } \\
\text { bulk } \\
\text { density }\end{array}$} \\
\hline & \multirow{2}{*}{$K$} & \multirow[t]{2}{*}{$A$} & \multirow{2}{*}{$r^{2} *$} & & & & \\
\hline & & & & C & $\rho_{\mathrm{c}}$ & $r^{2 *}$ & \\
\hline Free powder & $241 \mathrm{e}-4$ & 0.60 & 0.999 & $100 e-4$ & 0.24 & 0.996 & 0.20 \\
\hline $\begin{array}{l}\text { Granules from } \\
\text { fluidised bed }\end{array}$ & $12 \mathrm{e}-4$ & 0.09 & 0.994 & $1 \mathrm{e}-4$ & 0.07 & 0.999 & 0.07 \\
\hline $\begin{array}{l}\text { Granules from } \\
\text { high shear mixer }\end{array}$ & $115 e-4$ & 0.54 & 0.997 & $29 \mathrm{e}-4$ & 0.30 & 0.999 & 0.34 \\
\hline
\end{tabular}

* Corrected squared coefficient.

parameters given in Table 3 show that in the case of granules, $\rho_{\mathrm{c}}$ is lower or equal to the relative bulk density of granules before any compression. This can be explained by the fact that granules flow easily and rearrange to low density as they fill the die. Thus, at the beginning of the compression cycle, the upper punch already meets a strong resistance.

In conclusion, as opposed to the basic Heckel model, the modified model well integrates the packing stage in the compression cycle but, when a material is less compressible, the two models give similar results.

\subsubsection{Changes due to tapping}

As described above, granulation can modify the packing properties of the powder by structuring the particles and giving them a pseudo-spherical form. The $\mathrm{Yu}$ and Hall modification of Heckel equation (1) has been used to follow the changes in packing due to tapping (Fig. 5). This shows that the model gives a good agreement with the experimental results for both free powder and granules. The parameter $s$ (Table 4) can be taken to be a densification rate and $k$ is a constant characterising the initial state of a given material. Knowledge, of these parameters, allows prediction of the number of taps required to obtain a given tap density. This

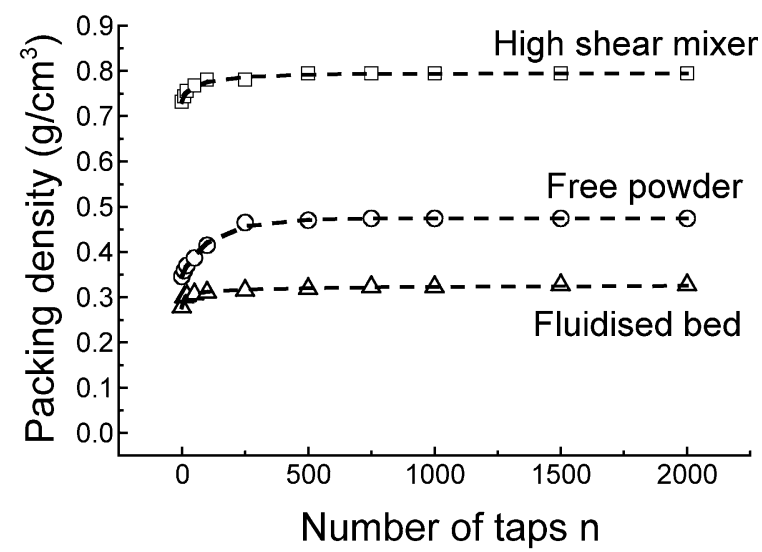

Fig. 5. Packing density versus number of taps. The dashed lines represent the model according to Yu and Hall [5] (Eq. (1)). 
Table 4

Parameters from the Yu and Hall [5] modification to the Heckel equation (1)

\begin{tabular}{llll}
\hline Materials & $s$ & $k$ & $r^{2}$ \\
\hline Free powder & 0.9 & 0.01 & 0.985 \\
$\begin{array}{l}\text { Granules from } \\
\text { fluidised bed } \\
\begin{array}{l}\text { Granules from high } \\
\text { shear mixer }\end{array}\end{array}$ & 0.3 & 0.27 & 0.981 \\
\hline * Corrected squared coefficient. & 0.6 & 0.06 & 0.905 \\
\hline
\end{tabular}

can be used to predict the final steady-state values without doing long experiments.

\subsection{Effect of granulation on reflectance spectrum of granules and their compacts}

Five measurements of reflectance are made for each sample and mean value is used. The variation factor was majored to $1 \%$ on the measure field $(400-700 \mathrm{~nm})$ and the relative error was estimated to $0.72 \%$ for five measurements.

\subsubsection{Influence of the granulation process}

Fig. 6 shows that the reflectance spectrum is influenced by granulation. A reflectance spectrum can be characterised by the position, the width and the height of its peak (Table 5). A first observation is that the three spectra are specific of blue materials (peak at $464 \mathrm{~nm}$ ).

The free powder mixture has a spectrum with a peak at $464 \mathrm{~nm}$, a height of 0.76 and a large width $(300 \mathrm{~nm})$. The end part of the curve is quite flat at a value of around 0.5 reflectance, indicating quite a high reflectance, giving an overall effect of clear blue.

Granules from the high shear mixer have a spectrum with a peak at $464 \mathrm{~nm}$, a width of $136 \mathrm{~nm}$ and a height of 0.5 . The final reflectance value is around 0.1 . These granules are the most absorbent and have an aspect of dark blue.

The granules from fluidised bed have a spectrum close to that of the free powder (a peak at $464 \mathrm{~nm}$ and a height of

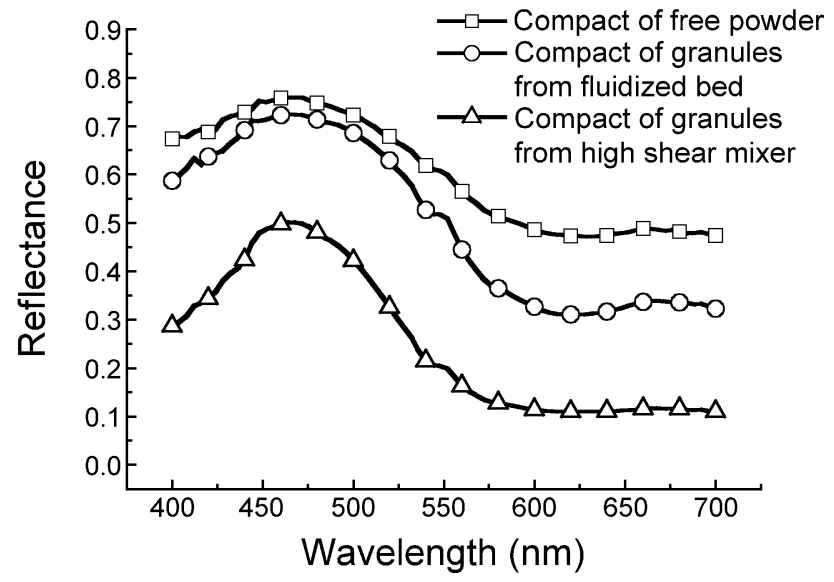

Fig. 6. Effect of granulation on the reflectance spectrum of compacts.
Table 5

Integration data of reflectance curves of compacts

\begin{tabular}{llll}
\hline Materials & $\begin{array}{l}\text { Peak } \\
(\mathrm{nm})\end{array}$ & $\begin{array}{l}\text { Width } \\
(\mathrm{nm})\end{array}$ & $\begin{array}{l}\text { Height } \\
(R \text { at 464 nm })\end{array}$ \\
\hline Free powder & 464 & 300 & 0.76 \\
Granules from fluidised bed & 464 & 184 & 0.73 \\
Granules from high shear mixer & 464 & 136 & 0.50 \\
\hline
\end{tabular}

0.73 ) but the peak width is less wide (184 nm versus $300 \mathrm{~nm}$ for the free powder) with a final reflectance value of around 0.35 . This shows an intermediate aspect between the granules from the high shear mixer and the free powder, but closer to the latter.

In conclusion, it has been shown that granulation improves the densification properties and at the same time modifies the reflectance spectrum and changes the intensity of the colour. Granulation by fluidisation gives granules with a colour (tint) close to that of the free powder, whereas, the high shear mixer, produces more dense granules that are bluer and more absorbent. The question remaining is whether this effect is due to the process (density and binder) or due to granule size.

\subsubsection{Effect of granule size}

Direct visual observations of granules produced by the high shear mixer, show a difference in the colour of according to granule size class. To quantify this observation, granules were separated into size classes by sieving, and the reflectance spectrum measured class by class for all the granules and a mean value is determined for each size class.

Two tendencies appear (Fig. 7): the two classes of spectra have the same shape but the coarse granules, above 1000 $\mu \mathrm{m}$, are shinier (the curve is $5 \%$ higher). These differences are more visible in the field of blue wavelengths (400-500 $\mathrm{nm})$ than in the red wavelengths (600-700 nm). However, the production of granules with a range of sizes can involve differences other than size. For example, granulation can involve differences according to size class in mixture

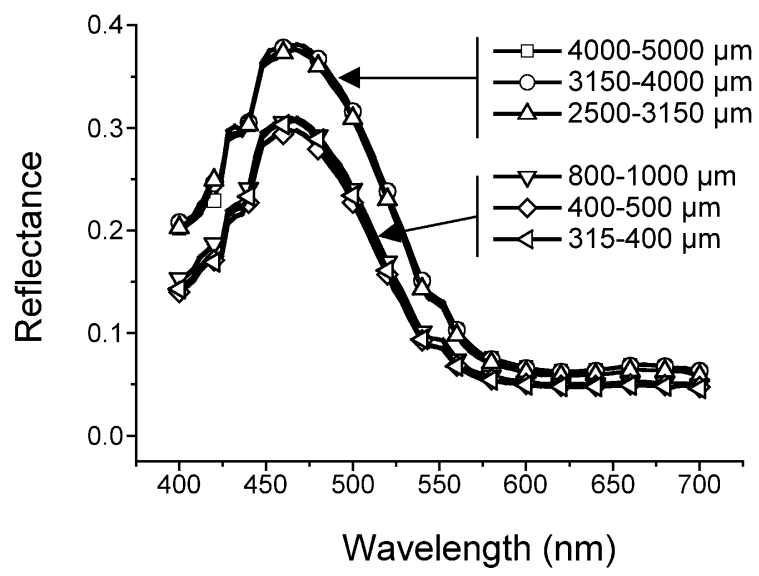

Fig. 7. Reflectance spectrum of granules as a function of granular classes. 
composition, binder content and structure, or differences of density. Investigation of this point requires further experiments in particular thermo-gravimetric measurements [14]

\section{Conclusions}

This study emphasises that granulation has an important impact on powder properties. Flow is improved both by size enlargement and by structuring the particles into pseudospherical granules. The two types of granulation used here produce granules with different mechanical strengths resulting in different behaviour under load. It is found that the Kuentz and Leuenberger modification to the Heckel equations gives good results for densification under load especially in the initial part of the curve where particles rearrange. Finally, granulation has an effect on the reflectance spectrum of powder and granules. In particular, high shear granulation favours the concentration of the pigment, and has thus an incidence on the colour of the granules. Moreover, we have seen, in the case of the high shear mixer, that granules have a different reflectance spectrum according to their granular classes.

\section{Nomenclature}

$d_{10}, d_{50}, d_{90}$ Particle diameter for which $10 \%, 50 \%$ and $90 \%$ in weight of the sample has a size under that dimension $(\mu \mathrm{m})$.

$\rho_{0} \quad$ Poured packing density.

$\rho_{n} \quad$ Packing density after $n$th tap.

$\rho_{\infty} \quad$ Tapped packing density.

CI Carr Index, that is, $\left(\rho_{\infty}-\rho_{0}\right) 100 / \rho_{\infty}$.

HR Hausner ratio, that is, $\rho_{\infty} / \rho_{0}$.

$k, s \quad$ Parameters of the modified Heckel equation (1) according to $\mathrm{Yu}$ and Hall [5].
$P \quad$ Compression pressure (MPa).

$\rho \quad$ Relative density.

$\rho_{\mathrm{c}} \quad$ Critical relative density in Eq. (3).

$K, A$ Constants of the Heckel equation, where $K$ $\left(\mathrm{MPa}^{-1}\right)$ equals the slope, and $A$ the intercept of the plot $\ln (1 /(1-\rho))$ with respect to $P$.

$C$ Constant $\left(\mathrm{MPa}^{-1}\right)$ of the modified Heckel equation (3) according to Kuentz and Leuenberger [13].

$R \quad$ Reflectance (reflexive light flux/incident light flux).

\section{References}

[1] B. N'Dri-Stempfer, D. Oulahna, O. Eterradossi, $3^{\text {ème }}$ Colloque Sciences et Technologie des Poudres, Récents Progrès en Génie des Procédés, Nancy, 2001.

[2] W. Pietsch, Size enlargement by agglomeration, in: J. Wiley (Ed.), Wiley, Chichester, 1991, pp. 4-39.

[3] H.H. Hausner, Int. J. Powder Metall. 3 (1967) 7.

[4] R.L. Carr, Br. Chem. Eng. 15 (1970) 1541.

[5] A.B. Yu, J.S. Hall, Powder Technol. 78 (1994) 247

[6] M.S. Mohammadi, N. Harnby, Powder Technol. 92 (1997) 1.

[7] P.-G. de Gennes, J. Colloid Interface Sci. 226 (2000) 1.

[8] AFNOR, Dictionnaire de Colorimétrie Théorique et Technique, AFNOR, Paris, 1989.

[9] G. Buxbaum (Ed.), Industrial Inorganic Pigments, Wiley-Vch, Weinheim, 1998.

[10] R.W. Heckel, Trans. Metall. Soc. AIME 221 (1961) 671.

[11] R.W. Heckel, Trans. Metall. Soc. AIME 221 (1961) 1001.

[12] C.M.D. Gabaude, M. Guillot, J.-C. Gautier, P. Saudemon, D. Chulia, J. Pharm. Sci. 88 (1999) 725.

[13] M. Kuentz, H. Leuenberger, J. Pharm. Sci. 88 (1999) 174.

[14] F. Cordier, D. Oulahna, J.A. Dodds, 2nd European Congress of Chemical Engineering, EFCE Event 606, Montpellier, 1999. 